\title{
MODEL STUDIES ON ICE-STREAM SURGING
}

\author{
by
}

U. Radok,

(Cooperative Institute of Research in Environmental Studies (CIRES), University of Colorado, Boulder, CO 80309, U.S.A.)

\section{B.J. McInnes, D. Jenssen, and W.F. Budd}

(Meteorology Department, University of Melbourne, Parkville, Victoria 3052, Australia)

\section{ABSTRACT}

A self-surging glacier model (Budd and McInnes, 1974; Budd, 1975), in which basal sliding is parameterized in terms of energy per unit area dissipated by basal friction, $\tau_{\mathrm{b}} V_{\mathrm{b}}$, has been extended to model the steady-state and time-dependent behaviour of eight Antarctic ice streams. Their basic characteristics were established with the working hypothesis of steady-state mass balance for the ice sheet as a whole, using a $20 \mathrm{~km}$ grid digitization of the surface and bedrock-elevation contours in Antarctica: glaciological and geophysical folio (Drewry, 1983). When the viscosity of the ice is lowered to values that are somewhat unrealistic for the present Antarctic ice, all the model ice streams enter a pulsating fast-sliding mode of flow in which the velocity reaches several $\mathrm{km} /$ year for periods ranging from fractions of a year to tens of years. Except for one ice stream (Slessor Glacier), no substantial surge-like advances were found, and even in that case no periodic surging regime developed. The pulses are tentatively attributed to processes at the grounding line, with the converging widthparameterization scheme in the surging velocity calculation as another complexity that is still being investigated. For the cyclic surging Medvezhi Glacier model (Budd and McInnes, 1978), it has been found that the model surges change to shorter pulses as the width-convergence rate is increased.

It is concluded that the special regime and topography of ice streams - net accumulation increasing along the strongly converging flow and removal of the ice by calving rather than ablation - impede the onset of periodic surging. However, more sophisticated parameterizations of the basal hydraulics now in development may well show that icestream surges after all are possible.

\section{INTRODUCTION}

The precise nature of what happens in surges remains in some doubt. Basically speaking, two possibilities exist, both involving water at the base of the ice. One possibility is that the water layer becomes thick enough to separate the ice from most of the protruding bedrock irregularities, lowering the restraints acting on the ice. The other possibility is that the ice rests on a layer of sediment which itself becomes easily deformable when saturated with water. In the first case, a glacier surge would develop when basal water, normally discharged as a glacier stream through one or more large conduits, is forced by their collapse to spread out into an extensive thin sheet below the glacier; this appears to have happened during the recent closely observed surge of Variegated Glacier (Kamb and others, 1985). In the second case, conditions for a surge could be created when the outflow of basal water is blocked by a combination of the overburden pressure and a rapidly changing resistance to internal deformation ("shear-stress gradient"; Robin, 1986). The resulting stagnant pool would favor the saturation of subglacial sediment at high water pressure and facilitate a rapid shearing of the sediment that could trigger a surge. It is also conceivable, however, that a sediment could have a stabilizing effect when its thickness and deformability are reduced by an increase in the sliding velocity (Alley and others, 1986).

These ideas are currently being developed into models that will in due course permit the essentials of the surging phenomenon to be reproduced. Any true surge must be expected to be an inherent feature of the glacier or ice-stream dynamics and involve, in the simplest terms, a self-induced relaxation of the frictional stresses that normally balance the gravitational forces acting on the ice. Such a relaxation was applied to a glacier model by Campbell and Rasmussen (1969); a similar experiment was reported recently by McMeekin and Johnson (1986). But these experiments by-passed the crucial question of how the relaxation comes about in reality.

The first, and so far only, model of truly self-induced surges has been put forward by Budd and McInnes (1974) and fully described by Budd (1975). The leading idea came from laboratory sliding experiments (Budd and others, 1979b) which showed that a transition to fast sliding occurred for a constant threshold value of the frictional energy dissipation per unit time and basal area (the product of basal shear stress and sliding velocity). In the Budd/ McInnes surging model, this parameter lowers the basal friction below the faster-moving parts of a glacier; these press on and accelerate the slower-moving ice ahead of them until the resulting surge has created a new low-stress and stagnant glacier shape. Accumulation on the upper glacier and ablation of its lower regions then gradually restore the shape that will produce another surge. In glaciers with large mass balances, a final state of steady fast sliding can develop for sufficiently large reductions in friction.

The model obviously oversimplifies the complex hydraulic processes taking place below glaciers, but its application to a number of well-documented glaciers (Budd and others, 1979a) produced surges in those known to have surged, and the right order of magnitudes of four surging characteristics (duration, recurrence period, maximum surging speed, and terminus advance) for a suitable selection of the two model parameters. One of these parameters, denoted by $\eta$, represents the deformability or "viscosity" of the ice and is determined primarily by its temperature. The other, $\phi$, is a multiplier applied to the frictional energy dissipation and can be interpreted as a "lubrication factor".

Its successes have made the model an obvious first tool for investigating the possible surging of Antarctic ice streams. But, in contrast to mountain glaciers, these ice streams receive their highest accumulation (instead of ablation) in their lower reaches at the "grounding line". Moreover, the discharge is usually impeded to a greater or lesser extent by ice shelves or ice tongues. On the other hand, the surging model's implied lubrication by frictional melt alone may be more applicable to ice streams than to glaciers, which have alternative sources of basal water.

A major problem is the lack of detailed information about the ice streams which usually originate in ill-defined 
source regions on the featureless Antarctic plateau and only become clearly visible ahead of gaps in the coastal mountains or through marginal crevasses near the grounding lines. Moreover, even after 30 years of expeditionary work during and since the IGY, many physical characteristics of the Antarctic ice sheet cannot yet be described from the available observations. The necessary background for an assessment of the surging problem can however be created by means of the simple working hypothesis that the ice sheet preserves its current thickness everywhere, with accumulation balancing the outward ice flow and any basal melt. Although this steady-state assumption is at best an approximation to reality, deviations from the steady state are too small to be clearly discerned from the available data, and appear to take the form of protracted slow growth followed by short intervals of accelerated calving (Jacobs and others, 1986). The description of the ice sheet by means of the steady-state assumption was pioneered by Budd and others (1970) and has been updated for this investigation with a digitized $20 \mathrm{~km}$ grid version of the most recent Antarctic data, published by the Scott Polar Research Institute, Cambridge, in Antarctica: glaciological and geophysical folio (Drewry, 1983).

A full set of maps of various derived ice-sheet characteristics has been published by Radok and others (1987). A critical evaluation of the gridded data created by the digitization of the Cambridge Folio surface- and bedrock-elevation maps has shown that the Folio's ice-volume estimate for East Antarctica is not consistent with the Folio's map contours. The estimate appears to have been derived directly from limited-area radar soundings only. As a result, the Folio's numerical estimate came out about $20 \%$ larger than all other estimates, including our own which derived from the uniform grid digitization of the Folio map contours. Users of the Folio should be aware of this discrepancy which also affects the total Antarctic ice volume.

Some uncertainty also attaches to our accumulation rates which were derived from various sources. An independent analysis of essentially the same data by Giovinetto and Bentley (1985) has given somewhat lower values everywhere which reflect mainly the different integrating procedures used. Our steady-state description clearly needs to be viewed bearing in mind this uncertainty and that of the other input data. It has, however, adequately served its immediate purpose of providing a starting point for time-dependent model experiments with a number of Antarctic ice streams.

\section{SURGING EXPERIMENTS FOR A REPRESENTATIVE}

\section{SAMPLE OF ANTARCTIC ICE STREAMS}

The ice streams to be modelled were selected to cover the full range of Antarctic conditions. Figure 1 shows eight ice-flow lines which provide representative examples of two distinct groups of ice streams. Those in the first group are usually described as "marine" and move over bedrock that lies well below sea-level. By contrast, the "continental" ice streams of the second group are based above sea-level along most of their lengths, although erosion has created deep depressions below their discharge regions in most cases. The steady-state working hypothesis can also be used to construct ice trajectories, age horizons, and temperature profiles in vertical sections along the ice streams.

Such longitudinal sections form the starting points for the model experiments. After identifying two flow lines that appear to enclose the total mass of an ice stream, the topographical parameters of the flow bands thus defined (surface and bedrock elevation, flow-band width, and ice thickness $Z$ ) and the accumulation values $A$ along the flow band were tabulated and used to calculate the longitudinal profile of the average balance velocity $V_{\mathrm{B}}$ from the equation of mass conservation ("continuity") along a flow line,

$$
\frac{\partial\left(V_{\mathrm{B}} Z\right)}{\partial s}+V_{\mathrm{B}} Z \frac{\partial \sin \psi^{\prime}}{\partial n}=A
$$

where $s$ and $n$ are coordinates along and across the flow line, and $\psi^{\prime}=\psi-\psi_{0}$ where the $\psi \mathrm{s}$ are the angles between

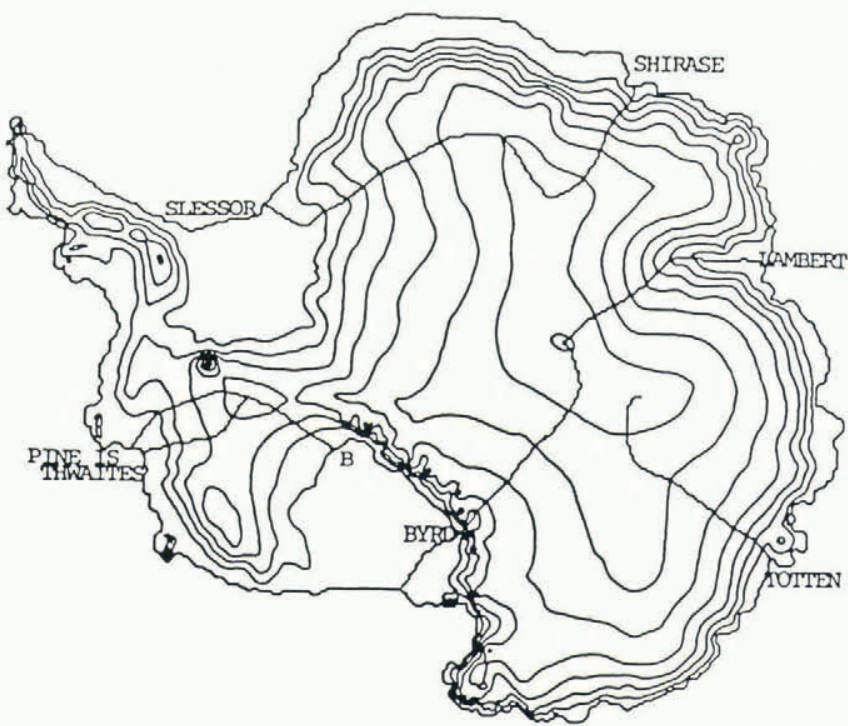

Fig. 1. Surface-elevation contours and the flow bands (broken lines) with central ice-flow lines of the ice streams studied using the Budd/McInnes surging model.

the flow lines and an arbitrary fixed reference direction ( $\psi=\psi_{0}$ for the flow line considered). The balance velocity follows by integration from the beginning of the flow line to the point considered $(s=X)$ as

$$
V_{\mathrm{B}_{\mathrm{X}}}=\frac{1}{Z_{\mathrm{X}}} \int_{0}^{X}\left[A-V_{\mathrm{B}} Z \frac{\partial \sin \psi}{\partial n}\right] \mathrm{d} s \text {. }
$$

These velocities were then used to tune the following formulae for stable deformation and sliding velocities:

The vertically averaged ice velocity $V_{\mathrm{i}}$ produced by internal deformation, following Budd and others (1984), is

$$
V_{\mathrm{i}}=k_{\mathrm{i}} Z \tau_{\mathrm{b}}{ }^{3} \exp \left(0.1 \theta_{\text {eff }}\right)
$$

where $\theta_{\text {eff }}$ is the average temperature of the lowest $5 \%$ of the ice. The constant $k_{\mathrm{i}}$ has been assigned the value 0.5 by matching $V_{\mathrm{i}}$ with the balance velocity $V_{\mathrm{B}}$ for the slowly moving ice not involved in the ice streams.

The stable sliding velocity $V_{S}$ must approximate the balance velocities of the ice sheet but be determined by the stresses. Following McInnes and Budd (1984), $V_{\mathrm{S}}$ is represented by

$$
\left.V_{\mathrm{S}}=k_{\mathrm{s}} \tau_{\mathrm{b}} \exp \left(0.1 \theta_{\mathrm{b}}\right) /\left[50+\left(Z_{*}+0.0035 Z_{*}^{2}\right)^{2}\right)\right] .
$$

Here $Z_{*}$ is the excess of the ice thickness above that causing the ice to float in water as deep as the bedrock depression, and is known as "thickness above buoyancy". The constant $k_{\mathrm{s}}$ has been assigned the value $1.5 \times 10^{8}$ $\left(\mathrm{m}^{3} \mathrm{bar}^{-1}\right.$ year $\left.{ }^{-1}\right)$ by matching $V_{\mathrm{S}}$ with the balance velocity $V_{\mathrm{B}}$ for a number of ice-stream regions. The complicated $Z_{*}$ function has been found empirically to improve the match and reflects the non-linear dependence of the sliding velocity on the effective normal stress.

Once the current thickness profile of each ice stream had been reproduced as a steady state, the stable sliding velocity component was replaced by the self-induced sliding embodied in the Budd/McInnes model; essentially this involved reducing the basal friction $\tau_{\mathrm{b}}$ by a factor $\left(1+\phi \tau_{\mathrm{b}} V\right)^{-1}$ (Budd and Radok, 1971), where $\phi$ can be interpreted as measuring the efficiency of the lubrication created by the viscous energy dissipation per unit time and area, $\tau_{\mathrm{b}} V$. For the detailed reasoning of the Budd/McInnes model, reference must be made to Budd (1975). The practical application of the model involves varying the parameters $\eta$ and $\phi$ over ranges suggested as physically appropriate by the earlier successful glacier-surging experiments, and constructing time histories of the changing flow-band thickness profiles. 


\section{RESULTS}

Most of the simulations of the complete West Antarctic cross-section through Pine Island Glacier and Ice Stream B continued for 15000 model years. The experiments for the remaining ice streams were limited to 5000 model years, which in all cases enabled the model to stabilize and indicate the trend produced by the parameters of the experiment. All experiments used a $20 \mathrm{~km}$ grid-point spacing and were designed to explore the possibility that the ice streams could thicken and change to a configuration that would spontaneously surge and create the present ice-stream shape as a transient.

The full results describing the behaviour of the different ice streams will be made available in a data report (paper in preparation by U. Radok and B.J. McInnes). Irrespective of their bedrock type, the ice streams reacted similarly to changes in the model parameters. For high viscosities, typical of the present ice sheet, and low lubrication factors found appropriate for the modelling of surging glaciers, all the thickness profiles remained close to their current shapes which formed the initial conditions in most experiments. When the viscosity was lowered and/or the lubrication factor raised beyond some distinct threshold values, the ice streams rapidly developed thinner profiles which were then maintained in approximate balance by fast sliding.

A representative set of results describing that last type of development for the West Antarctic flow band is shown in Figures 2 and 3. This experiment used a large lubrication factor $\left(10^{-4} \mathrm{bar}^{-1} \mathrm{~m}^{-1} \mathrm{a}\right)$ and an unrealistically low viscosity (100 bar a) as an encouragement for surges to develop. Instead, the enhanced sliding created a negative balance which rapidly thinned the ice on both sides of the ice divide and produced a new steady-state shape at the left-hand (Pine Island Bay) end of the cross-section. By contrast, the right-hand (Ross Sea) end of the cross-section emerged from the initial negative-balance thousand years with a slightly positive balance that led to a continual expansion of the ice on to the continental shelf. The shelf edge was actually reached in another experiment after more than 100000 years, but over such long periods it is unrealistic to neglect the response of the bedrock, let alone climatic changes.

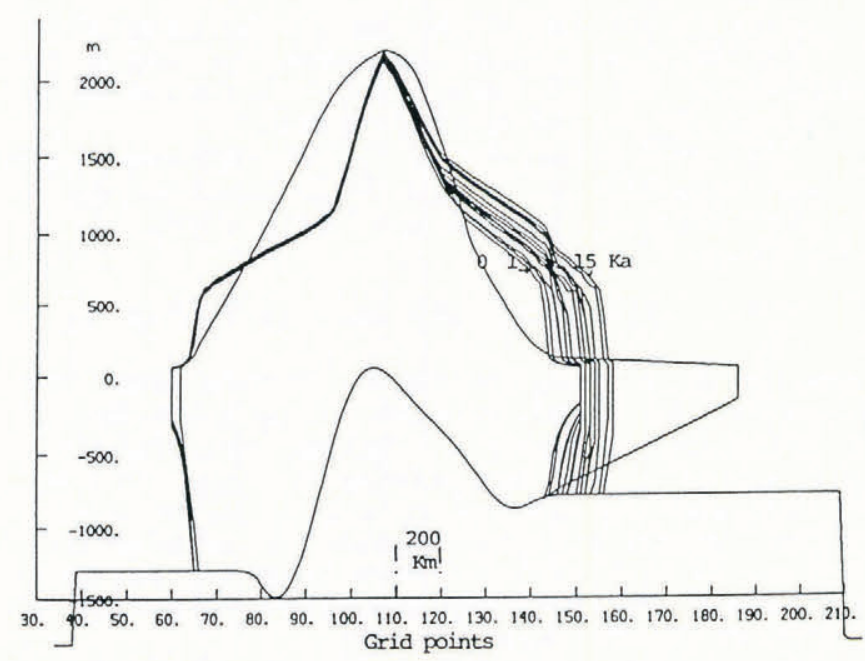

Fig. 2. Ice-thickness profiles of a cross-section through West Antarctica from Pine Island Glacier (left) to Ice Stream B (right), obtained at 1000 model-year intervals during a simulation that started from the current profile $(0)$. The model rapidly changes the shape of the profile to an equilibrium configuration for Pine Island Glacier, whereas Ice Stream B advances with velocity pulses and ultimately reaches the edge of the continental shelf near grid point 210. Strain-rates of 0.01 /year and $0.005 /$ year have been assumed, respectively, for the Pine Island Glacier tongue and for the Ross Ice Shelf down-stream from Ice Stream B (which is not modelled in detail). The horizontal scale is numbered in $20 \mathrm{~km}$ grid intervals $(200 \mathrm{~km}$ between marks). (After McInnes and others, 1986.)

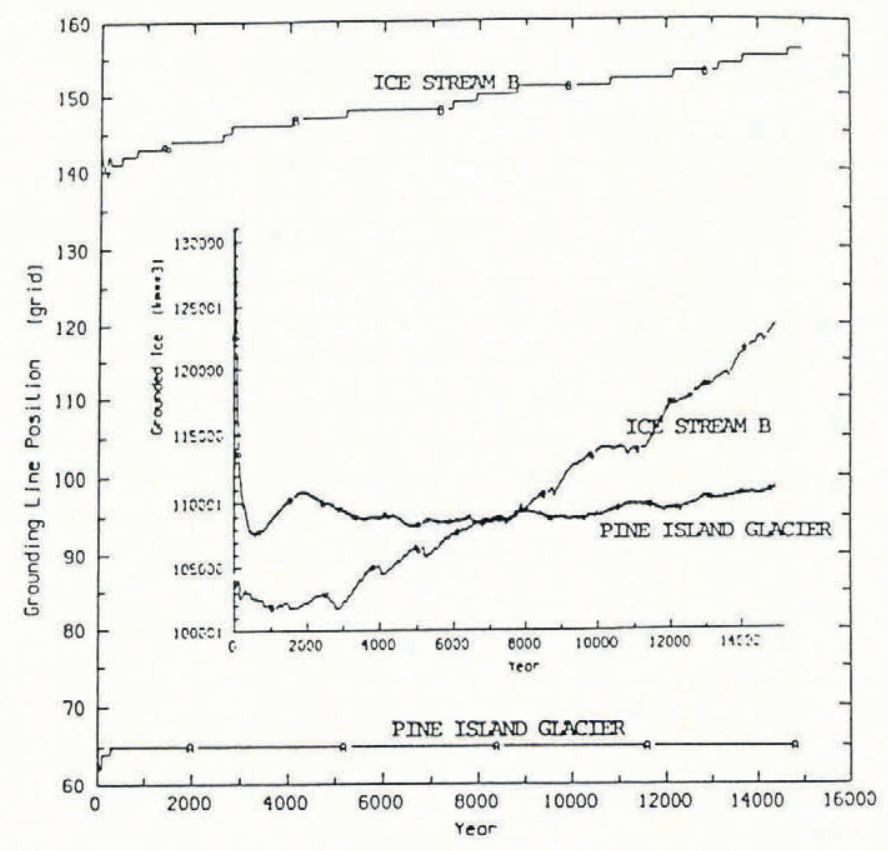

Fig. 3. Time series of grounding-line positions corresponding to Figure 2. The insert shows the associated changes in the grounded ice volumes (after McInnes and others, 1986).

It is intriguing that the negative balance of Ice Stream B during the initial 10000 years has been confirmed by recent measurements (Whillans and others, 1987). However, too much must not be made of this, in view of the unrealistic parameter values needed to make the model ice stream undergo the development described above. The only pointer to possible surges or unusually rapid flow in this and other experiments was that the changes to thinner profiles invariably took place in an unsteady manner through numerous "velocity pulses" in which the maximum sliding velocities rapidly increased to several kilometres per year. The nature of these pulses will be further discussed below. Most of them were of short duration, lasting from less than a year to several years; their temporary or persistent occurrence appears to be unaffected by the level of the bedrock, and in general produced no substantial mass discharges into the ocean. In one experiment for Slessor Glacier, some of the initial pulses last a few decades but again did not develop into cyclic surges.

Some of the model experiments aimed to clarify the effects of a reduction in the back pressure exerted on an ice stream by its ice shelf. Figure 4 shows two sequences of ice-thickness profiles* along the Pine Island Bay-Ross Ice Shelf flow band, produced by increasing the accumulation rates by $50 \%$ over their current values and at the same time imposing higher deformation rates than those that exist at present in the floating ice at both ends of the flow band. As argued in detail by Budd and others (1987), these conditions can be taken to represent a possible future climatic scenario due to enhanced atmospheric $\mathrm{CO}_{2}$. The model results suggest that effects on the ice streams would depend mainly on the changes in the ice-shelf deformation rate resulting from higher ocean temperature (it is easy to show that the temperatures of the main ice mass would be very slow to respond to a climatic warming). However, again no surges of substantial magnitude occurred in these model simulations.

*In the model, calving occurs when the thickness of the ice shelf drops below $200 \mathrm{~m}$ at a grid point. If calving removes all floating ice, the model creates an ice shelf extending one grid interval $(20 \mathrm{~km})$ beyond the now grounded last grid point. Thus, the plotted terminus can be substantially thicker than $200 \mathrm{~m}$. 
according to Figure 3, retained its approximate position in a region of mass influx since the thickening of the ice, according to Equation (4), reduces its sliding velocity, and terminates the velocity pulse.

This process could not be substantially altered by increasing or decreasing the assumed ice-shelf strain-rate or the mass-balance profile. However, in the present model investigation the grounding-line position is not being monitored between grid points; instead, the grounding line advances/retreats by a full $20 \mathrm{~km}$ grid interval whenever conditions for grounding are met or not met (viz. that the ice thickness has become greater, or remained less, than approximately 1.1 times the bedrock depth below sea-level). More refined treatments of this process and of the interaction between grounded and floating ice could produce substantial changes in the velocity pulses.

Another relevant factor appears to be the changing width of the glacier or ice stream. This features not only in integrated centre-line mass balance but also in the condition that the base-stress anomalies when integrated over the entire area must approximately vanish for equilibrium. In reality, this condition applies only to the ice primarily involved in the accelerated sliding and not to the part of the glacier or ice stream that reacts slowly to its changed topography. Experiments with different assumed widthconvergence rates along Medvezhi Glacier have shown that its well-defined cyclic surges decay to shorter pulses for uniform convergence rates as low as $2: 1$; similar studies are needed for ice streams, but these must at the same time take into account also the grounding-line process mentioned earlier.

\section{CONCLUSION}

The model experiments outlined in this paper, and fully described in a series of U.S. Department of Energy reports (McInnes and others, 1986; Radok and others, 1986) for a representative sample of Antarctic ice streams, have shown that their current thickness profiles can be reproduced as steady-state configurations with ice deformation and sliding relationships (derived from laboratory experiments and glacier observations, taking account of shear stresses as well as the basal normal stress not supported by buoyancy) with parameter values well inside their uncertainty ranges. The same holds for the self-surging glacier model of Budd and McInnes (1974) when viscosities corresponding to present Antarctic ice temperatures are used. Lower viscosities and increased lubrication factors produce velocities that are out of balance with the observed accumulation; this leads to thinner profiles with approximately zero net balance. Such a trend is in accord with recent measurements on Ice Stream B but has been achieved in the model with unrealistic parameters (warmer ice and/or increased lubrication) which point to a need for improved parameterizations.

Altering some of the external factors (such as the assumed rate of snow accumulation) and boundary conditions (such as the assumed restraint exerted by a terminal ice shelf) in accordance with predicted climatic changes produces gradual ice-stream advances or retreats as quasistable developments. That leaves as a key question: whether or not some or all of the ice streams could periodically accelerate their already fast sliding and suddenly increase their current discharges into the ocean.

The answer depends on the as yet unknown hydraulic processes taking place below the ice streams. For a preliminary assessment, the model experiments reported here have used the most basic fact of the ice-stream hydraulics: that, with the present Antarctic ice temperatures, water below the ice streams can arise only from a combination of geothermal and frictional heating. The experiments show that the latter had little effect on the ice-stream motion and the existing thickness profiles for moderate and high values of the ice viscosity (which translates longitudinal stresses into displacements) and low values of the lubrication factor (which translates the frictional energy dissipation into reductions of basal friction). For viscosities below, and lubrication factors above, well-defined threshold values, the model ice streams went into marked velocity oscillations which averaged to a fast-sliding motion that in general produced thinner and flatter ice-thickness profiles. In some experiments, designed to produce ice-sheet growth, the ice advanced to the edges of the continental shelf but again without substantial surges. Both the thinning/retreat and the thickening/advance could be modulated by changing the strain-rate prescribed for the floating terminal ice; these strain-rates simulated the restraining effects on ice shelves or ice tongues exerted by pinning points and by the sides of embayments. With minor differences in threshold values, both marine ice streams, based below sea-level, and ice streams on rock above sea-level conformed to the same broad behaviour pattern.

The large velocity pulses have not yet been firmly explained but they seem to be linked to grounding-line events and the changing flow band widths. In essence, they may be regarded as a controlled non-linear reaction to basal melt that cannot be dispersed by the model without allowing more adequately for the detailed hydraulics processes below the ice streams.

Finally, it should be noted that some of the factors neglected in the model experiments described here (e.g. lateral restraints, and various ways of disposing of water formed below ice streams) would favour greater steadiness rather than intermittency. A basic difference between the Antarctic ice streams and surging mountain glaciers is that in Antarctica the accumulation rate increases from the high inland source regions to the low ice-stream-discharge regions near the coast, instead of in the opposite sense that characterizes mountain glaciers. Moreover, in place of the ablation areas on glaciers the ice streams typically end in ice that is partly floating in containing embayments. It appears at least possible that the implied strong mass-flux convergence in ice streams leads to fast sliding, with steady or fluctuating velocities as two possible states of ice streams and without the intervening periodic alternation of fastsliding advance and stagnation/retreat found for mountain glaciers. But the jury will remain out on whether icestream surges are possible until the basal processes have come to be modelled in greater detail and realism.

\section{REFERENCES}

Alley, R.B., D.D. Blankenship, S.T. Rooney, and C.R. Bentley. 1986. In Till deformation and ice stream flow: $a$ numerical model. Chapman Conference on Fast Glacier Flow, Whistler, B.C., May 1986.

Budd, W.F. 1975. A first simple model for periodically self-surging glaciers. J. Glaciol., 14(70), 3-21.

Budd, W.F. and B.J. McInnes. 1974. Modeling periodically surging glaciers. Science, 186(4167), 925-927.

Budd, W.F. and B.J. McInnes. 1978. The periodically surging Medvezhi Glacier matched with a general ice flow model. Mater. Glyatsiol. Issled. Khron. Obsuzhdeniya 32, 247-260.

Budd, W.F. and U. Radok. 1971. Glaciers and other large ice masses. Rep. Prog. Phys., 34(1), 1-70.

Budd, W.F., D. Jenssen, and U. Radok. 1970. Derived physical characteristics of the Antarctic ice sheet. ANARE Interim Rep.. Ser. A(IV). Glaciology. (Publ. 120.)

Budd, W.F., B.J. McInnes, and I.N. Smith. 1979a. Derivation of ice sliding properties from the numerical modelling of surging ice masses. J. Glaciol., 23(89), 420-421.

Budd, W.F., P.L. Keage, and N.A. Blundy. 1979b. Empirical studies of ice sliding. J. Glaciol., 23(89), 157-170.

Budd, W.F., D. Jenssen, and B.J. McInnes. 1985. Numerical modelling of ice stream flow with sliding. ANARE Res. Notes 28, 130-137.

Budd, W.F., B.J. McInnes, D. Jenssen, and I.N. Smith 1987. Modelling the response of the West Antarctic ice sheet to a climatic warming. In Veen, C.J. van der and J. Oerlemans, eds. Dynamics of the West Antarctic Ice Sheet. Proceedings of a Workshop held in Utrecht, May 6-8, 1985. Dordrecht, etc., D. Reidel Publishing Company, 321-358.

Campbell, W.J. and L.A. Rasmussen. 1969. Three-dimensional surges and recoveries in a numerical glacier model. Can.J. Earth Sci., 6(4, Pt. 2), 979-986.

Drewry, D.J., ed. 1983. Antarctica: glaciological and geophysical folio. Cambridge, University of Cambridge. Scott Polar Research Institute. 
Giovinetto, M.B. and C.R. Bentley. 1985. Surface balance in ice drainage systems of Antarctica. Antarct. J. U.S., 20(4), 6-13.

Jacobs, S.S., D.R. MacAyeal, and J.L. Ardai, jr. 1986. The recent advance of the Ross Ice Shelf, Antarctica. $J$. Glaciol., 32(112), 464-474.

Kamb, B., and 7 others. 1985. Glacier surge mechanism: 1982-1983 surge of Variegated Glacier, Alaska. Science, 227(4686), 469-479.

McInnes, B.J. and W.F. Budd. 1984. A cross-sectional model for West Antarctica. Ann. Glaciol., 5, 95-99.

McInnes, B.J., W.F. Budd, I.N. Smith, and U. Radok. 1986. On the surging potential of polar ice streams. Part III. Sliding and surging analyses for two West Antarctic ice streams. Washington, DC, U.S. Department of Energy. (Rep. DOE/ER/60197-4.)

McMeeking, R.M. and R.E. Johnson. 1986. On the mechanics of surging glaciers. J. Glaciol., 32(110), 120-132.

Radok, U., T.J. Brown, D. Jenssen, I.N. Smith, and W.F. Budd. 1986. On the surging potential of polar ice streams. Part IV. Antarctic ice accumulation basins and their main discharge regions. Washington, DC, U.S. Department of Energy. (Rep. DOE/ER/60197-5.)

Radok, U., D. Jenssen, and B.J. McInnes. 1987. Antarctic surges - $a$ clear and present danger? On the surging potential of polar ice streams. Washington, DC, U.S. Department of Energy. (Rep. DOE/ER/60197-H1.)

Robin, G. de Q. 1986. Water blocking beneath glaciers and ice streams. In Till deformation and ice stream flow: a numerical model. Chapman Conference on Fast Glacier Flow, Whistler, B.C., May 1986.

Whillans, I.M., J. Bolzan, and S. Shabtaie. 1987. Velocity of ice streams B and C, Antarctica. J. Geophys. Res., 92(B9), 8895-8902. 